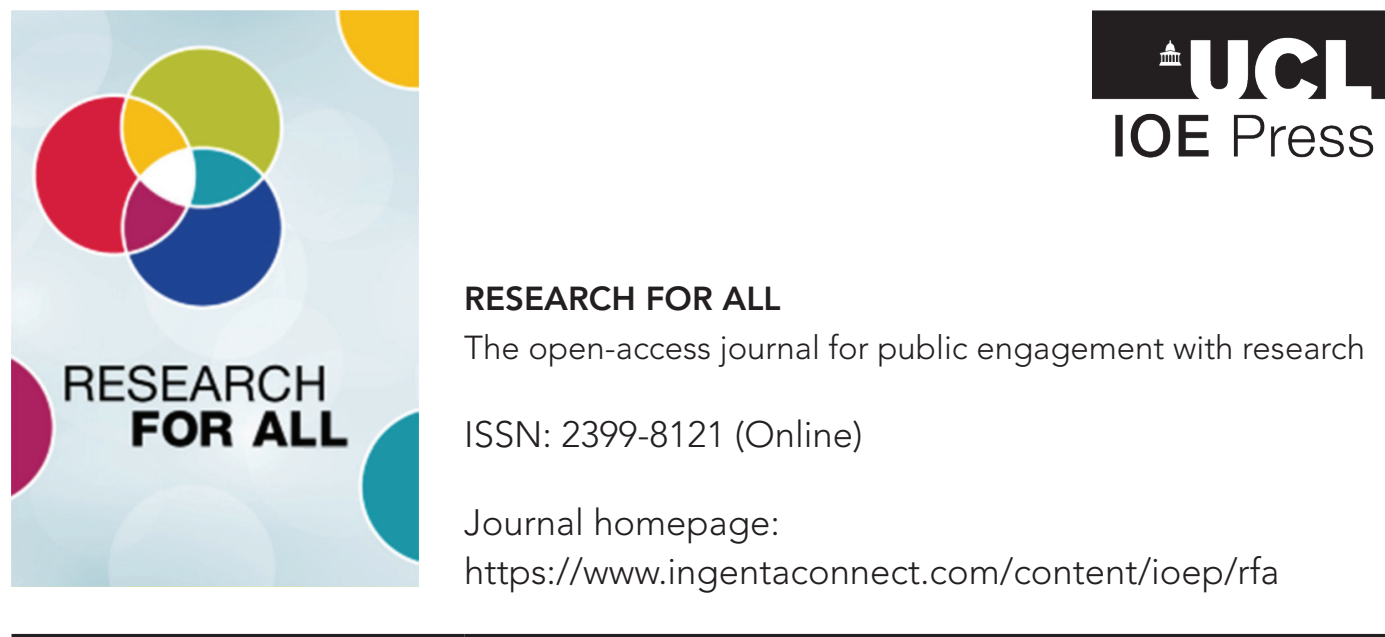

\title{
Poetry as method - trying to see the world differently
}

\author{
Elizabeth Chapman Hoult, Helen Mort, Kate Pahl(D) and Zanib Rasool(D)
}

\section{How to cite this article}

Hoult, E.C., Mort, H., Pahl, K. and Rasool, Z. (2020) 'Poetry as method - trying to see the world differently'. Research for All, 4 (1): 87-101. DOI https://doi.org/10.18546/RFA.04.1.07

Submission date: 4 December 2018

Acceptance date: 16 August 2019

Publication date: 1 February 2020

\section{Peer review}

This article has been peer reviewed through the journal's standard double-blind peer review, where both the reviewers and authors are anonymized during review.

\section{Copyright}

(C) Copyright 2020 Hoult, Mort, Pahl and Rasool. This is an Open Access article distributed under the terms of the Creative Commons Attribution Licence (CC BY) 4.0 https://creativecommons.org/licenses/by/4.0/, which permits unrestricted use, distribution and reproduction in any medium, provided the original author and source are credited.

\section{Open access}

Research for All is a peer-reviewed open-access journal. 


\title{
Poetry as method - trying to see the world differently
}

\author{
Elizabeth Chapman Hoult* - University of Northumbria, UK \\ Helen Mort - Manchester Metropolitan University, UK \\ Kate Pahl - Manchester Metropolitan University, UK \\ Zanib Rasool - University of Sheffield, UK
}

\begin{abstract}
Research with communities, even co-produced research with a commitment to social justice, can be limited by its expression in conventional disciplinary language and format. Vibrant, warm and sometimes complex encounters with community partners become contained through the gesture of representation. In this sense, 'writing up' can actually become a kind of slow violence towards participants, projects and ourselves. As a less conventional and containable form of expression, poetry offers an alternative to the power games of researching 'on' communities and writing it up. It is excessive in the sense that it goes beyond the cycles of reduction and representation, allowing the expression of subjective (and perhaps sometimes even contradictory) impressions from participants. In this cowritten paper we explore poetry as a social research method through subjective testimony and in the light of our Connected Communities-funded projects (Imagine, Threads of Time and Taking Yourself Seriously), where poetry as method came to the fore as a way of hearing and representing voices differently.
\end{abstract}

Keywords: poetry as method, poetry in communities, poetry as enquiry

\section{Key messages}

- Poetry can be helpful as a way of collecting data from and with communities and making meaning from that data.

- Poetry has the potential to forge a connection between writers and readers (or community participants and academics as writers and readers of each other's work).

- Poetry has the potential to help communities and academics to say the unsayable, to move beyond the ineffable and, as such, move us beyond representation.

\section{Introduction}

In this article we exemplify and explore the purposes of poetry in relation to social research in general and co-produced research with communities in particular. Our contention is that poetry can open up to lived experience and enable dissonant, complex voices to be heard. We each come from different traditions of writing. Helen 
is a poet. Kate and Zanib together were the lead researchers on the communityoriented Imagine project in Rotherham (Rasool, 2017; Campbell et al., 2018). Elizabeth conducted a study of science fiction in a prison for the Imagine project, and has explored literary analysis as social research method in her published work (Hoult, 2012). Here, we explore the various, complex, open ways that poetry can both resist interpretative standpoints and open up new and original forms of enquiry.

This paper takes as its premise the idea that models of writing that are most prevalent in social science do not account for lived experience, unless they are accompanied by other forms of expression. The case for this has been made for social science work in general (see Richardson, 1997). The problem is particularly pressing for research that takes place in communities and is sometimes co-produced with them. Co-produced research leads to different strands of enquiry - often led by community research teams and devised and constructed with communities. The outputs can reside within a number of different art forms and ways of knowing and representing the world (Campbell et al., 2018). Our work draws on a joint project, Imagine, in which poetry as method surfaced in a variety of ways, as well as on our lived experience and a shared interest in arts methods in our academic work.

\section{Our projects}

The four of us (Zanib, Elizabeth, Kate and Helen) have worked on linked funded projects that were nurtured by a large project funded by the Economic and Social Research Council called Imagine, which explored the cultural context of civic engagement. All the individual projects were underpinned by the core research questions of Imagine. Two of these questions were: 'What role can imagining better futures play in capturing and sustaining enthusiasm for change?' and 'Is community research being transformed by developments in social research methodology, particularly the development of collaborative methods?'

The Imagine project encouraged community partners to develop, shape and write up research that explored the ways in which everyday cultures were experienced, and the relationship between culture and civic engagement (Williams, 1989). One of the core concerns of Imagine was to develop an understanding of the ways in which communities can imagine hopeful futures; another was the development of a knowledge base about the possibilities of the use of co-production methodologies to influence social change (see Banks et al., 2019).

Many of our projects used arts-based methodologies to pursue this enquiry. In our funding proposal, two of us (Zanib and Kate) developed the idea to work with South Asian women poets together with published poets in order to recover the lost heritage of women who wrote poetry in Pakistan. We situated the work in the Northern town of Rotherham. As part of the Rotherham project, we drew on a number of methodologies, including oral history, arts practice, collaborative ethnography and poetry as method, which we wrote up in a co-written book (Campbell et al., 2018).

In the Imagine poetry project in Rotherham, we worked with diverse communities, particularly with British Asian girls and young women. We found that poetry was often a helpful medium of expression for them. While we recognize that not everyone sees 'poetry' as for them, our experience is that words, oral language, modes of expression, can offer ways in which young people can articulate their concerns, whether this be through rap, film, music, visual art or song poems (Pahl, 2019). Conceptualizations of literacy that see 'school literacy' as the only literacy practices that are important manage to elide young people's complex multimodal productions and do not recognize home 
literacy practices (Pahl, 2014). While poetry might be seen as an elite art form, more recent forms, such as rap and slam poetry, have led to a burgeoning of interest in spoken word poetry (Jones and Curwood, 2019).

Threads of Time was a project that emerged from Imagine, as part of a 'followon funding' Arts and Humanities Research Council (AHRC) grant. This was also codevised with a group of British Asian women. Lasting over a summer, and culminating in a book of poems, the project involved a poet (Helen Mort, author) and a community researcher (Zanib Rasool, author) working with a small group of British Asian girls to write poetry together. Helen delivered four sessions with the girls. One of the sessions took place in a local park. The girls were recruited through Zanib Rasool's contacts within the British Asian community in Rotherham

Zanib was also involved in a third project, Taking Yourself Seriously, which involved working with artists and poets to co-produce a book about the experiences of three generations of British Asian girls and women. The Taking Yourselves Seriously project was an AHRC-funded follow-on project that explored the relationship between social cohesion and arts methodologies. This was developed in response to her previous projects, and used poetry as method as well as visual arts. For that project, Kate (author) worked with poets Andrew McMillan and Helen Mort (author) in a school in Rotherham.

Elizabeth's contribution to Imagine drew on literary methods more widely than a specific focus on poetry to consider the applications of open reading techniques to the way that men in prison talked about their futures - Reading Resilience in a Prison Community. She used science fiction films to explore the ability to tolerate multiple meanings and to talk about global and personal futures in ways that straightforward interviews would not allow. While that project is not a feature of this paper, the thinking that went into it (see Hoult, 2019), and the discussions with other project leaders here, were a part of the intellectual development of the project.

\section{Poetry as method}

Our argument here is that poetic methods can surface voices in different ways. Social science methodologies that explore everyday cultural practices recognize the material and storied nature of everyday life (Hurdley, 2013; Highmore, 2014). Everyday cultural practice resides within a shifting materially situated landscape. The opening up of the research methods landscape has included a turn to more embodied and materially situated modes of enquiry. A recognition of the visual and sensory nature of the world has been developed through sensory and visual ethnographic methods (Pink, 2009). Everyday language has its own cadences and rhythms, complexities, ellipses and oblique moments. Hidden within language are 'small stories' and aesthetic forms (Georgakopoulou, 2007, 2015). The 'art of common talk' (Carter, 2004) includes a lived aesthetics, beauty and forms of resistance that are not always oriented towards representation (MacLure, 2011; Ivinson, 2018). Arts methodologies acknowledge the way that language, as well as visual and gestural modes, is aesthetically and symbolically shaped (Willis, 2000). The unknown is part of the picture - things not said, or not articulated in language, can be captured through an awareness of aesthetics and form (Vasudevan, 2011). The aesthetics of everyday life brings a much-needed understanding of how beauty and the shaping of language can inform understandings of the world in new and surprising ways (Pahl, 2014). Poetry is a mode of writing that brings in living knowledge that is aesthetically shaped, being a concentrated way of expressing complex ideas. Affect, feeling and lived experience seep more strongly into 
poetic forms. Many people do not find traditional research methods congruent with lived experience, with the stories, silences and feelings of the everyday (Stewart, 2007). Poetry, as a form of representation, can present an opportunity to listen to participants in different ways. Resisting categorization, it can offer a space to describe the world in ways that are in the 'not yet', the unknown (Vasudevan, 2011). Poems resist single narratives and enable self-expression. In Walt Whitman's 'Song of Myself' (1892), the narrator celebrates the complexity of the individual ('I am large, I contain multitudes') and the inevitability of contradiction. In a sense, this could be a description of the poem itself, of the 'multitudes' poetry might embody. Poetry is increasingly used as an accessible method of working with diverse groups of people who might otherwise not engage with the written word, and creative writing workshops can be used in flexible ways. The Derbyshire Poet Laureate scheme (2005-15) run by Derbyshire County Council is just one initiative that exemplifies poetry's versatility as a means of engaging participants, involving a single 'laureate' poet working with groups ranging from primary school children to elderly people diagnosed with Alzheimer's disease and home library service users to facilitate self-expression through poetry. In some cases, the poems produced in these workshops were deliberately written as 'group poems', assembled from the words of different participants and rejecting a notion of single voice (see Made in Derbyshire (n.d.) for more details about poetry in the Made in Derbyshire scheme).

\section{A note on "us"}

In poet Zaffar Kunial's first collection Us (2018), the title poem problematizes the notion of a singular, collective voice. As the narrator declares in the opening stanza:

If you ask me, us takes in undulations each wave in the sea, all insides compressed as if from one coast, you could reach out to the next ...

There's a playful subversion at work in the first line ('If you ask me ...'), the poet foregrounding the piece with an expression of opinion. The word 'us' is also contained in the word 'undulations', if the reader cares to look for it, but it is fragmented and changed, one letter at the start of the word and one at the end. Throughout the poem, the narrator continues to challenge the idea that 'us' can really be a way of ascribing a singular voice to many people. They note that in Midlands English dialect, 'us' is sometimes used to mean 'me' ('tell us where yer from' - Kunial's father was from Kashmir and in his childhood this might actually have been a phrase used in a challenging way, used to imply divisive lack of belonging). 'When it comes to us', the poem argues, 'colour me unsure'. The attempt to speak with one voice might be a doomed (and charged) endeavour.

As such, we have chosen to reject a singular notion of 'us' in our collective authorship of this paper, and instead present four accounts of how poetry has formed part of our co-created practice. Through this, we hope to match the methodology used to the argument proposed, and to take in the 'undulations' contained in 'us'.

All four of us have academic and/or professional connections to poetry and see literature in general as core to our intellectual identities. Therefore, we want to explore the power of poetry to work beyond the limits of gathering data or solving problems.

The three 'undulations' we present here are variously explored through individually written pieces of writing. In these sections, the word 'we' is used, but it is 
used with uncertainty, with awareness of how it might be problematic to even imply a collective voice within this paper. Taken together with the 'undulations', this paper presents a less conventional approach to representing authorial voice, and as such emulates what poetry can do in social research contexts.

\section{The problem of secondary representation}

Unknowing as a stance of enquiry is increasingly seen as useful as an orientating standpoint towards co-produced research (Vasudevan, 2011; Atkinson, 2018). It is hard to put unknowing into academic writing, however. As Richardson (1997) argues, academic writing is neither a transparent representation of reality nor neutral. To quote Elizabeth Hoult (2012: n.p.):

The adoption of a style of writing characterized by certainty, logical linearity, and authority moves in a realm characterized by uncertainty and unknowing is ... problematic. It is a defended form of writing up that covers up more than it reveals and, as a result, it feels dishonest, and it lacks warmth. Crucially, it does not help very much.

Here, we take seriously Zanib Rasool's (2017: 313) assertion in her reflections on community-based research that 'poetry captures raw emotions in a way that interviews cannot', and we explore this in the light of: (1) a particular co-produced piece of research between academic, poetic and community partners (Threads of Time); and (2) theoretical considerations of the particular contribution of poetry from literary and social theory. Poetry has a peculiar and unspeakable ability to join writers and readers together in ways that transcend both place and hierarchy. We will explore here whether it is possible to argue that this works in three ways:

1. as a way of collecting data and making meaning from that data from communities

2. as a way of forging a connection between writers and readers (or community participants and academics as writers and readers of each other's work)

3. finally, for both, of saying the unsayable, of moving beyond the ineffable and, as such, moving us beyond representation.

Here, we suggest that poetry can play a particular part in direct representation of subjects in ways that, along with post-structuralist feminist research stances (see, for example, Richardson, 1997; Hoult, 2012), attempt to represent voices and lives without destroying or colonizing them. To quote Hélène Cixous (1996: 85-6) on that notion of 'saying the unsayable':

Writing is the passageway, the entrance, the exit, the dwelling place of the other in me - the other that I am and am not, that I don't know how to be, but that I feel passing, that makes me live - that tears me apart, disturbs me, changes me, who? - a feminine one, a masculine one, some? several, some unknown, which is indeed what gives me the desire to know and from which all life soars. This peopling gives neither rest nor security, always disturbs the relationship to 'reality', produces an uncertainty that gets in the way of the subject's socialisation.

We also acknowledge, however, that 'subject's socialisation' is particularly fraught in the academic realm, and that this has serious implications for researchers and subjects alike, and especially so when the researcher is working in a post-colonial and/ or feminist commitment to praxis. Richa Nagar has problematized the relationship 
between reflexivity, positionality and the language of collaboration with skill, and we do not seek here to present easy solutions or resolutions, in particular to the question of how much is revealed or covered over in an academic text that is co-produced with community partners. Nagar, writing with Susan Geiger, challenges the demand for reflexive academic writers who collaborate with community partners to give in to the demands to 'uncover ourselves in specific ways for academic consumption', partly, they point out, because of the inequitable demands for feminist researchers who work in collaborative partnerships with participants to 'uncover' in ways that other researchers operating in other paradigms do not (Nagar and Geiger, 2014: 84); but, perhaps more fundamentally, because 'uncovering ourselves in these terms contradicts the purpose of problematizing the essentialist nature of social categories, which are, in reality, created, enacted and transformed' (ibid.). It should be noted, for example, that an earlier iteration of this article included a fourth undulation that was a raw and direct response from Elizabeth to Hafsah Wahid's (2017) beautiful poem 'Lily', quoted below. The ethical and professional problems of including such a reading in an article produced for 'academic consumption' were, in the end, too difficult to navigate in this form, and the undulation was removed. Our suggestion here is that poetry could allow all participants to divest authentically in ways that resist the confessional direct autobiographical references of the reflexive account, but that have the protection of poetic camouflage. As Yeats put it in his poem 'A Coat' (1916), 'There's more enterprise in walking naked' than producing writing that is weighed down with theoretical (and in Yeats's case, mythological) referencing. But poetry provides a safe place for readers and writers to be radically open without being trapped by the literality of print and its removal of the right to erasure. To put it more bluntly, Elizabeth should have written a poem in response to Hafsah's poem. We are suggesting that there is an immediacy to a poem that is different from other kinds of texts. Karin Barber (2007: 6) writes, 'There is no doubt that when we meet certain kinds of texts - many kinds, in fact - there is a sense of encounter with something other and almost beyond comprehension; yet at the same time, curiously close.' Here, we suggest that the poem, either produced by community partners or read with them, has a particular capacity to engender this sense of encounter, not just with itself as a text but with the participating partner, and thus to begin to bridge the academic/community binary in ways that are not without problems, but that allow a curious closeness to develop in ways that other kinds of texts used in such work do not.

We draw on two concepts here to help us stretch the argument. The first is Maggie MacLure's (2011) extended consideration of stuttering as a way of understanding what poetry does in a research sense. The second is Ted Hughes's (1994) concept of catching poems as a way of thinking about the way that knowledge is formed in ways that differ to the conventional notion of thought preceding representation in prosaic language. We deliberately queer the theory/creativity binary by involving ourselves as writers, readers and researchers in this text. As Maggie MacLure (2011: 999) says:

In some places, there is a kind of division of labour in research, where those who engage with theory tend not to do much empirical research, and people who are employed on grants or contracts for specific research projects are not allowed or encouraged to be theoretically engaged.

Bridges-Rhoads and Van Cleave (2017: 298) ask 'what happens when we write posthumanism, qualitative enquiry and early literacy together'? Taking our cue from them, we ask a similar question: 'What happens when we write poetry, poetry analysis 
and co-production methodologies with communities together?' It produces a similar group of what they call 'entanglements' (ibid.).

In her influential poem 'Diving into the Wreck' (1973), Adrienne Rich meditates on the problems of representation, silence, who has the right to tell a story, and on the impossibility of ever getting close to what is real in any account of that reality. Underpinned by references to gendered and racial violence, she positions herself as part of the problem, as well as the solution. The impossibility of escaping the power plays of representation need not be the reason for not doing it. Rather, she seems to be suggesting, the only way of writing about the lives and needs of ourselves and others authentically is to do so in full acknowledgement of the struggle and ellipses in the account, and in full acknowledgement of the violence we inevitably commit when we tell a story - any story - about the other:
We are, I am, you are
by cowardice or courage
the one who find our way
back to this scene
carrying a knife, a camera
a book of myths
in which
our names do not appear.

We cannot get close to the scene, to 'it', without referring to the stories that circulate and precede our encounter, or without academic or psychic defences. We do great damage in our investigative efforts. But without those efforts, some of those stories would never be told, leading to more silence and more marginalization. Poetry can act as a creative interruption, an answer to Maggie MacLure's (2011: 1002) question: 'One productive question for research, and for education, might be how to work the ruins of representation at least long enough to engage the bodily intensities of affect that swim in language ... and mobilize these creatively'.

\section{First undulation: Zanib - ways out}

I was a child that stuttered and got ignored and learnt to be silent, I am a woman whose words have been strangulated in to submission.

I now articulate my grievances in a different way for I have learned the art of writing poetry in my heart.

The ink bleeds and covers my words and hides them from your unkind gaze. With each thumping heart beat my voice grows stronger and more powerful.

Can you hear me?

Are you listening to me?

Why are you not answering me back?

Why are you not talking over me?

Why are you not challenging me to be silent?

Poetry flows through me, the words come to me when I least expect them, on the bus, in the middle of the night while the world sleeps, I play around with words of discontentment in my head, words that only the oppressed can understand well. At night when I am all alone, my words are strong, but in the daytime my little words get kicked around like a football, they get bruised and damaged. My broken words lie dying and are quickly put together lovingly by me in poetic form to articulate 'women's 
experiences', the barriers, the boundaries and the constraints; when my words speak of women's emotional embodiment, they come alive again. Poetry brings powerful narratives of women's lives to the public domain and challenges counter-narratives.

A research design that uses arts methodology can go much further beyond the superficial to explore women's multilayered and gendered experiences, and engage new participants to research and create new spaces with fluid boundaries for research to take place. As argued by Back and Puwar (2012: 18), 'creative or art based methods in social research opens a space outside of the boundaries of traditional methods of data gathering, developing creative, public and novel modes of doing imaginative and critical sociological research'.

Working recently on three collaborative arts-based research projects (Imagine, Threads of Time and Taking Yourself Seriously), I advocate for arts as a methodology for understanding the lives of women that have previously been on the margins of research. These arts projects captured the emotional journeys of women, and contributed to academic research a multiplicity of voices on the variety of female experiences. The projects gave women who are under-represented in research the opportunity to tell their stories through writing and poetry. 'Poetry allows individuals to utilize their marginality', arguing that 'it is essential that Black women recognize the special vantage point our marginality gives us and make use of this perspective to criticize the dominant racist, classist, sexist hegemony and create a counter hegemony' (hooks, 1984: 2).

Liz Yorke's (1991) stance resonates with me and the research I have been undertaking. She argues for poetic language 'to transform women's relations to myth, to history, and to representation generally, through retelling of the histories, the stories undertaken when women "wake up from among the dead"' (ibid.: 10).

Hafsah Wahid (2017), 19, observed a dead lily on the ground and writes in her poem 'Lily':

I was yanked away from my family and friends

My petals were pulled painfully away from me

I have now been left in the dark to be stood on repeatedly.

This kind of powerful research data can only come out of arts methodology, where young women can tentatively express their position in a patriarchal and unequal world. It feels like I have also roused from the dead as I submerge myself in poetry. I have now found a place for my lost words. Hafsah states, 'there was a lily on the ground near the bandstand that had been stamped on, lifeless and fading away that caught my eye. I cannot explain why' (personal communication). Hafsah is perhaps too young to understand the emotions her poem 'Lily' resonates in us. Collecting research data from a feminist epistemology through creative writing and poetry enables us to go deeper into the lives of women on the margins of society, to capture their personal experiences through their descriptions of their feelings and emotions' (Crotty, 1998). In this way, we can begin to understand the realities of being the 'other'.

\section{Second undulation: Helen - poetry and failure}

I stand in a corner of the supermarket lit by the screen of my phone, trying to type in the words before they leave me. I stay in the cafe scribbling while they're trying to close up. I miss my stop on the train because I'm finding a rhyme that might catch what I mean better than I can know. I cross things out and start again: the words on the page 
just don't correspond to the sensation I feel and the ideas that generates. I'm failing again. And my failure is a new poem.

In 2013, when I was gathering data for a PhD on the connections between poetry and neuroscience, I interviewed a number of contemporary poets about their writing process, facing them with the elusive question: 'Where do you think your poems come from?' As I carried out these anonymous interviews, I was gripped by the same feeling I get when I sit down to write a poem: recognition without understanding. In each encounter, when we tried to talk about the process of creating a poem, it always became clear that neither of us could fix an accurate description, but that we strongly identified each other's failure to do so. The dialogues began to cohere around ideas of failure and flux:

Almost all the poetry I write ... doesn't come from intent. My editor at $[\mathrm{x}]$ said to me, 'you don't really know what you're doing until you're half-way through do you?' ... It is a visitation in a kind of way ... to not be visited is what all writers fear. Nobody quite knows what happens when images stir lines or provoke lines. (Poet W)

One of my interviewees - a celebrated figure in British poetry - spoke at length about Robert Frost's idea of the poem as a 'momentary stay against confusion' (Frost, 1939), and how - ironically - it might offer that 'stay' by engendering further confusion:

I've occasionally thought, as someone who makes patterns, metaphors, that unless I can impose those patterns on the world somehow then the world's going to seem too chaotic for me. It's about finding some kind of order in disorder. But every time I think I've established a credible, explicable account of why I write, I write a poem that doesn't fit any of those definitions. It keeps changing. ... I sometimes think poetry is always going to be a groping towards meaning and significance that ultimately can't be achieved or defined. But that doesn't stop us wanting to howl at the moon or create local conditions of significance which we can live within. (Poet D)

Poets are very poor at defining poetry, I'd suggest, because poetry has a singular relationship with inarticulacy and silence. Glyn Maxwell (2012: 2) writes about this at length in his ars poetica, On Poetry: 'Poets work with two materials, one's black, one's white ... You want to hear the whiteness eating? Write out the lyrics of a song you love ...'. I have always been drawn to write poetry because, in the rest of my life, I'm plagued by the feeling that I'm never quite saying what I mean, never expressing myself properly. But - in some strange way - that feeling of inarticulacy can be heightened when I write a poem. I'm acutely aware of the blank space that surrounds the text, literally and metaphorically. And that explicit acknowledgement of partiality, silence and 'failure' makes the poem feel like a more accurate representation of life. Much of what we write seems to be founded on the underlying assumption that things can be explained and catalogued exhaustively - that the world can be mapped. Poetry, by contrast, is based on the assumption that it can't be. As Poet D said in our interview, 'Poetry has always been in conflict with dominant modes and it's often in conflict with what we think of as "information".' 


\section{Third undulation: Kate - fleeting encounters with poetry - telling things slant}

For Tom and Lisa

Tell all the truth, But tell it slant (Emily Dickinson, 1868)

Living in the world is a constant juggle between the now, the then and what is to come. In her diaries, Virginia Woolf (1978) described the act of stepping over a puddle as being both immense and fleeting: it takes in the world, but it is also mundane. Within the moment, huge things can happen. Icarus can fall from the sky, Eurydice can vanish into the underworld, and people can decide to leave this world.

In Semblance and Event, Brian Massumi (2011: 3) tried to pin down the ways in which the moment works in relation to the creative act, 'the coming-into-its-own out of a prior moreness of the world's general always-going-on, and the unity of the holdingtogether of phases arcing to a culmination in just this singular way'. I am interested in the 'singular way' of this coming together. What is hard is to find ways to capture the fleeting event in all its fullness, 'The qualitative dimension of the event is the how it happens, co-felt, in the immediacy of its now unfolding. How-now' (ibid.: 4). 'All this is felt' (ibid.: 3). We are caught up in the world, its immediacy. Out of the corners of our eyes come thoughts and ideas. We are all caught in the 'webs of significance' (Geertz, 1973: 5).

What does that mean for research in educational settings? I think of the poetry session that Andrew McMillan (poet) and I co-taught yesterday, and moments when the writing somehow arced into something else, a singular moment. Pieces of experience rushed in from other places. A child lay in a hospital bed. A mother tended to her children. A girl danced in her bedroom. A child turned into gold. These pieces of language, lived abstraction, the 'semblances' in Massumi's (2011) words, come from other places but are born again in the now. The poem is something half seen, half formed but emergent, urgent, often not heard, but sensed in the corner of the eye:

Above us in the summer skies

Was a cloud that caught my eye

It was so white and so very high above

And when I looked up, it had never been.

$\cdots$

And even that kiss, I would long since have forgotten it

If the cloud had not been there

(Brecht, 'Erinnerung an die Marie A.' ('Remembrance of Marie A.'), 1927)

In this poem, discussed by the philosopher Ernst Bloch (1969) and cited by Johan Siebers (in press), the cloud 'retains the fleeting moment in memory by interrupting it. It vanishes with the moment, but functions as both a negation and a promise or expectation'. In the half-light of the poetic encounter come these phrases: 'these are the pearls that were his eyes' (Shakespeare, The Tempest); 'In the end is my beginning' (T.S. Eliot, Little Gidding); 'My heart aches and a drowsy numbness fills my soul' (Keats, 'Ode to a Nightingale').

So, our research understandings come in half-lights, half-truths, half coming to know. Our consciousness is unable to comprehend everything. We 'stutter', in Maggie MacLure's words (2011). Our inability to grasp things is riven with our own reflexive consciousness, affects, emotion, embodiment. Poetry is a place where we can risk 
language in the moment, to create something new, a creative interruption in the fabric of the world, both mundane and extraordinary:

The still point of the turning world (T.S. Eliot, Burnt Norton, 1936)

\section{Bringing it all together}

This article has moved through a number of voices. At the core of our argument is that poetry as a mode of enquiry surfaces different kinds of knowledge. We recognize the value of social science methods in opening up debate and informing policy, but we wonder what would happen if the word 'research' was conceptualized differently? Here, we see how the method of reading 'Lily', of co-feeling, of stuttering and dissolving our singularities in favour of 'us', has brought us close to a lived reality that has implications for the ways research is understood. Our work has been concerned with failure, telling things slant, stuttering and being trampled on. What can that tell us about the world? Abi Hackett et al. (in press) write about the ways in which in post-industrial spaces people's everyday lives, their affective experience of the everyday, is often elided in favour of skills-based, instrumentalized versions of literacy. Our reading of 'Lily' calls us into a world where the affective matters, and education has to take account of the ordinary affects that cross its path (Stewart, 2007). Drawing together these threads, we will begin to map out an orientation from a poetry as method perspective that can support a rethinking of methods to account for the things that cannot be said within traditional social science.

Here, we explore in more detail what these methods can help us with:

1. Decolonizing methodologies. In their book Indigenous and Decolonizing Studies in Education, Tuhiwai Smith et al. (2019) highlight the ways in which knowledge resides in indigenous communities and that such forms of knowledge exist in different forms of writing, which resist academic discourses. Citation practices and modes of writing often lead to assertions of whiteness and leave out scholars of colour (Ahmed, 2017). By bringing emotion into research studies, new kinds of language are possible. We have also drawn on feminist writing to make sense of the world differently (Nagar, 2014).

2. Pedagogy and practice. Poetry is a disobedient pedagogy (Atkinson, 2018). It calls into question ways of knowing that are settled, certain and fixed. Instead, it asks for a radical open-ness to what could be, an awareness of process and emergence (Manning, 2016). In this process, pedagogies of emergence come to the fore, the stutter, the not quite said, the sense of 'with-ness' (Ehret, 2018).

3. Staying within a space of failure. Failure provides a space to value the forgotten, the lost and the not-ness of the world (Halberstam 2011). Poetry is in itself a form of failure, as each poem succeeds another, as the inability of language to describe what is in the world is what poetry is built upon (McMillan, in conversation). This arc of failure is the space of poetry, but also the space of building ideas together, failing and then failing better, as Samuel Beckett (1983) wrote. Learning is predicated upon this process.

4. Embodiment and creative practice. Arts methods are distinctive in that they privilege embodiment, uncertainty and emergence (Facer and Pahl, 2017). Studio as method provides a way to think about modes of thinking that are collective, but also to try out new ideas (Pahl and Pool, 2018). Our work together here was begun in a room in Sheffield; since then, we have emailed, discussed, met and not met. Sometimes it has been hard to keep going. Our practice is embodied, happening 
beside a park, in a conversation and across continents, as well as within particular sites and spaces.

\section{Conclusions}

This paper has illustrated a more democratic, searching, questioning methodology than the conventional social research model it has sought to critique. Poet Don Paterson has suggested that poems rely on connotation rather than denotation (Paterson, 2018). Writing a poem that will be read by others is an inherently democratic process - although the poem usually privileges one particular standpoint (that of the author or of the poem's narrator) or set of experiences in its writing, it creates a space for the reader too, allowing room for ambiguity and for a range of responses. As many of our readings in this paper have shown, interacting with a poem leaves room for our own personal interpretations. Where the poem is also the product of a workshop environment where the writer has been interacting with others, the process is even more inherently collaborative. As such, our 'undulations' bear witness to a different way of approaching research with communities through poetry. Through them, we have attempted to show that 'Resistant to capture by ideology or language, wonder could be the proper business, not only of philosophy, but also of qualitative inquiry' (MacLure, 2011: 1004).

Poetry - with its ability to contain paradox - is perhaps our best means of preserving that 'wonder', but also our best means of approaching research that may be genuinely co-created, containing a multitude of voices, rather than the single-author stance that 'writing up' often imposes.

\section{Acknowledgements}

We would like to acknowledge the support of the Economic and Social Research Council (ESK/002686-2) and the Arts and Humanities Research Council (AH/P009573), who funded these projects.

\section{Notes on the contributors}

Elizabeth Chapman Hoult is Professor of Education at the University of Northumbria. Her core research interest is how and why some individuals and communities are able to resist disadvantage and marginalization and instead succeed and thrive as learners. Her work draws on the epistemologies and methodologies of education and literary theory in order to develop plural and deep understandings of resilience and transformational learning experiences.

Helen Mort is five-times winner of the Foyle Young Poets of the Year Competition. Helen's work has been shortlisted for the Costa Prize and the T.S. Eliot Prize. She is a Fellow of the Royal Society of Literature. Her poetry collections Division Street (2013) and No Map Could Show Them (2016) are published by Chatto \& Windus. She is a lecturer in creative writing at Manchester Metropolitan University.

Kate Pahl is Professor and Faculty Head of Research and Knowledge Exchange and Head of the Education and Social Research Institute at Manchester Metropolitan University. Her research has been concerned with literacy practices in communities, drawing on arts and humanities methodologies. She has been involved with many projects funded through the AHRC Connected Communities programme. All of these 
projects have been co-produced with community partners and have involved drawing on the knowledge within communities to work together to produce living knowledge.

Zanib Rasool has worked for thirty years in the voluntary/community sector and is currently undertaking doctoral research in education at the University of Sheffield. She was a community researcher on the Imagine project. She is co-editor of Re-imagining Contested Communities: Connecting Rotherham through research (Policy Press, 2018). She was community researcher on Threads of Time, a co-produced participatory art project, and Taking Yourselves Seriously: Exploring Artistic Approaches to Social Cohesion, which focused on the life trajectories of women from Pakistani heritage backgrounds.

\section{References}

Ahmed, S. (2017) Living a Feminist Life. Durham, NC: Duke University Press.

Atkinson, D. (2018) Art, Disobedience, and Ethics: The adventure of pedagogy. Cham: Palgrave Macmillan.

Back, L. and Puwar, N. (2012) 'A manifesto for living methods: Privations and capacities'. Sociological Review, 60 (S1), 6-17.

Banks, S., Hart, A., Pahl, K. and Ward, P. (eds) (2019) Co-Producing Research: A community development approach. Bristol: Policy Press.

Barber, K. (2007) The Anthropology of Texts, Persons and Publics: Oral and written culture in Africa and beyond. Cambridge: Cambridge University Press.

Beckett, S. (1983) Worstward Ho. New York: Grove Press.

Bloch, E. (1969) 'Über den Begriff Weisheit'. In Philosophische Aufsätze zur objektiven Phantasie. Frankfurt: Suhrkamp.

Brecht, B. (1927) 'Reminiscence of Marie A'. In Die Hauspostille. New York: Grove Press.

Bridges-Rhoads, S. and Van Cleave, J. (2017) 'Writing posthumanism, qualitative enquiry and early literacy'. Journal of Early Childhood Literacy, 17 (3), 297-314.

Campbell, E., Pahl, K., Pente, E. and Rasool, Z. (eds) (2018) Re-Imagining Contested Communities: Connecting Rotherham through research. Bristol: Policy Press.

Carter, R. (2004) Language and Creativity: The art of common talk. London: Routledge.

Cixous, H. (1996) 'Sorties: Out and out: Attacks/ways out/forays'. In Cixous, H. and Clément, C. The Newly Born Woman. Trans. Wing, B. London: I.B. Tauris Publishers, 63-132.

Crotty, M. (1998) The Foundations of Social Research: Meaning and perspective in the research process. London: SAGE Publications.

Dickinson, E. (1868) 'Tell the truth but tell it slant'. In Complete Poems (2016). London: Faber.

Ehret, C. (2018) 'Moments of teaching and learning in a children's hospital: Affects, textures, and temporalities'. Anthropology and Education Quarterly, 49 (1), 53-71.

Eliot, T.S. (1936) 'Burnt Norton'. In Four Quartets (2001). London: Faber.

Facer, K. and Pahl, K. (eds) (2017) Valuing Interdisciplinary Collaborative Research: Beyond impact. Bristol: Policy Press.

Frost, R. (1939) 'The figure a poem make'. Preface to Collected Poems of Robert Frost. New York: Henry Holt.

Geertz, C. (1973) The Interpretation of Cultures: Selected essays. New York: Basic Books

Georgakopoulou, A. (2007) Small Stories, Interaction and Identities. Amsterdam: John Benjamins Publishing Company.

Georgakopoulou, A. (2015) 'Small stories research: Methods - analysis - outreach'. In De Fina, A. and Georgakopoulou, A. (eds) The Handbook of Narrative Analysis. Chichester: Wiley Blackwell, 255-71.

Hackett, A., Pahl, K., Truman, S., Escott, H. and McLean Davies L. (in press). 'The capaciousness of "no": Affective refusals as literacy practices'. Reading Research Quarterly.

Halberstam, J. (2011) The Queer Art of Failure. Durham, NC: Duke University Press.

Highmore, B. (2014) The Great Indoors: At home in the modern British house. London: Profile Books.

hooks, b. (1984) 'Black women: Shaping feminist theory'. In hooks, b. Feminist Theory: From margin to center. Boston: South End Press, 1-15. 
Hoult, E.C. (2012) 'Recognizing and escaping the sham: Authority moves, truth claims and the fiction of academic writing about adult learning'. InterActions: UCLA Journal of Education and Information Studies, 8 (2), 1-24. Online. https://escholarship.org/uc/item/2164s2gc (accessed 5 November 2019).

Hoult, E.C. (2019) 'On not doing co-produced research: The methodological possibilities and limitations of co-producing research with participants in a prison'. In Banks, S., Hart, A., Pahl, K. and Ward, P. (eds) Co-Producing Research: A community development approach. Bristol: Policy Press, 135-52.

Hughes, T. (1994) Winter Pollen: Occasional prose. Ed. Scammell, W. London: Faber and Faber.

Hurdley, R. (2013) Home, Materiality, Memory and Belonging: Keeping culture. Basingstoke: Palgrave Macmillan.

Ivinson, G. (2018) 'Re-imagining Bernstein's restricted codes'. European Educational Research Journal, 17 (4), 539-54.

Jones, K. and Curwood, J. (2019) 'Spoken word poetry as a tool for critical literacy development'. Paper presented at the New South Wales English Teachers Association Conference, Sydney, June.

Kunial, Z. (2018) Us. London: Faber and Faber.

MacLure, M. (2011) 'Qualitative inquiry: Where are the ruins?'. Qualitative Inquiry, 17 (10), 997-1005.

Made in Derbyshire (n.d.) 'Derbyshire Poet Laureates past and present'. Online. www.madeinderbyshire.org/news/derbyshire-poet-laureates-past-and-present (accessed 29 November 2019).

Manning, E. (2016) The Minor Gesture. Durham, NC: Duke University Press.

Massumi, B. (2011) Semblance and Event: Activist philosophy and the occurrent arts. Cambridge, MA: MIT Press.

Maxwell, G. (2012) On Poetry. London: Oberon Books.

Nagar, R. (2014) Muddying the Waters: Coauthoring feminisms across scholarship and activism. Urbana: University of Illinois Press

Nagar, R. and Geiger, S. (2014) 'Reflexivity, positionality, and languages of collaboration in feminist fieldwork'. In Nagar, R. Muddying the Waters: Coauthoring feminisms across scholarship and activism. Urbana: University of Illinois Press, 81-104.

Pahl, K. (2014) 'The aesthetics of everyday literacies: Home writing practices in a British Asian household'. Anthropology and Education Quarterly, 45 (3), 293-311.

Pahl, K.H. (2019) 'Recognizing young people's civic engagement practices: Re-thinking literacy ontologies through co-production'. Studies in Social Justice, 13 (1), 20-39.

Pahl, K.H. and Pool, S. (2018) 'Re-imagining artistic subjectivities within community projects'. Open Library of Humanities, 4 (2), Article 2, 1-22. Online. https://doi.org/10.16995/olh.248 (accessed 5 November 2019).

Paterson, D. (2018) The Poem: Lyric, sign, metre. London: Faber and Faber.

Pink, S. (2009) Doing Sensory Ethnography. London: SAGE Publications.

Rasool, Z. (2017) 'Collaborative writing practices: Imagining better research partnerships'. Research for All, 1 (2), 310-22.

Rich, A. (1973) Diving into the Wreck: Poems, 1971-1972. New York: W.W. Norton and Company.

Richardson, L. (1997) Fields of Play: Constructing an academic life. New Brunswick, NJ: Rutgers University Press.

Siebers, J. (in press) 'Preface: The future of wisdom'. Futures, 115.

Stewart, K. (2007) Ordinary Affects. Durham, NC: Duke University Press.

Tuhiwai Smith, L., Tuck, E. and Yang, K.W. (2019) Indigenous and Decolonizing Studies in Education: Mapping the long view. New York: Routledge.

Vasudevan, L. (2011) 'An invitation to unknowing'. Teachers College Record, 113 (6), 1154-74.

Wahid, H. (2017) 'Lily'. In Threads of Time: A book of poems. Sheffield: University of Sheffield.

Whitman, W. (1892) 'Song of Myself'. In Leaves of Grass (2002). New York: WW Norton and Company.

Williams, R. (1989) Resources of Hope: Culture, democracy, socialism. London: Verso.

Willis, P. (2000) The Ethnographic Imagination. Cambridge: Polity Press.

Woolf, V. (1978) 'A Sketch of the Past'. Moments of Being. London: Triad Granada.

Yeats, W.B. (1916) 'A Coat'. In Yeats, W.B. Responsibilities and Other Poems. New York: Macmillan Company, 80.

Yorke, L. (1991) Impertinent Voices: Subversive strategies in contemporary women's poetry. London: Routledge. 